\title{
\begin{tabular}{l|l|l} 
Jurnal Eksplorasi Akuntansi & $\begin{array}{l}\text { Vol. 1, No 3, Seri D, Agustus 2019, Hal 1354-1362 } \\
\text { ISSN : 2656-3649 (Online) } \\
\text { http://jea.ppj.unp.ac.id/index.php/jea/issue/view/11 }\end{array}$
\end{tabular}
}

\section{PENGARUH PENGENDALIAN INTERNAL DAN MORALITAS INDIVIDU TERHADAP FRAUD ORDERAN PADA JASA TRANSPORTASI BERBASIS ONLINE GO-JEK di KOTA PADANG}

\author{
Jana Haniful Khair ${ }^{1}$, Halmawati ${ }^{2}$ \\ 1) Alumni Jurusan Akuntansi Fakultas Ekonomi, Universitas Negeri Padang \\ ${ }^{2)}$ Jurusan Akuntansi Fakultas Ekonomi, Universitas Negeri Padang \\ *Korespondensil: jana030794@gmail.com
}

\begin{abstract}
This study is to study the effect of internal control and individual morality on fraudulent transportation orders based online at PT. Go-Jek, City of Padang. This research is quantitative research with primary data from questionnaires and using a Likert scale. The population of this research is a car and motorcycle driver, PT. Go-Jek in Padang City. The purposive sampling technique of sampling and a sample of 150 respondents. Data analysis technique is data quality test, classic assumption test and hypothesis test consisting of multiple linear regression tests using SPSS 23.0 for Windows. The results of this study indicate that internal control and individual morality have a negative and significant influence on order fraud
\end{abstract}

Keywords: Internal Control, Individual Morality; and fraud orders

How to cite (APA $6^{\text {th }}$ style)

Khair, J.H., \& Halmawati. (2019). Pengaruh Pengendalian Internal dan Moralitas Individu terhadap Fraud Orderan pada Jasa Transportasi Berbasis Online PT.Go-Jek Kota Padang. Jurnal Eksplorasi Akuntansi, 1(3), Seri D, 1354-1362.

\section{PENDAHULUAN}

Perkembangan zaman pada sekarang ini telah menciptakan suatu kecanggihan transportasi, kalau ingin berpergian dalam kota tanpa menggunakan kendaraan pribadi biasanya kita harus menunggu di tepi jalan untuk menunggu angkutan umum dan sangat menghabiskan waktu. Masyarakat sangat membutukan transportasi dalam melaksanakan rutinitasnya, tidak semua masyarakat yang mampu untuk mempunyai kendaraan sendiri, maka dari peluang itu hadirlah beberapa perusahaan yang mencoba mencari keuntungan dengan bergerak di bidang jasa transportasi, saat ini yang sedang marak yaitu Go-Jek dengan pemesanan menggunakan aplikasi telepon yang berbasis android dan iOS (Apple).

PT.Go-Jek adalah salah satu perusahaan transportasi online yang sedang berkembang pesat di kota Padang. Pendiri dari PT.Go-Jek adalah Nadiem Makarim tamatan dari Universitas Harvard Business School. Sistem kerja yang dimiliki pihak PT.Go-Jek berbasis aplikasi online ini cenderung terjadinya kecurangan (fraud) yang dilakukan oleh driver Go-Jek. Alison (2006) Kecurangan merupakan bentuk penipuan yang sengaja dilakukan sehingga dapat menimbulkan kerugian tanpa disadari oleh pihak yang dirugikan tersebut dan memberikan keuntungan bagi 
pelaku kecurangan.Albrecht (2014)menyebutkan bahwa terdapat tiga faktor yang dapat menyebabkan terjadinyafraud. Ketiga faktor tersebut adalah tekanan situasional (situational pressures),kesempatan untuk melakukan fraud (opportunities to commit fraud) dan integritaspersonal (personal integrity/character),Kecurangan yang dilakukan driver Go-Jek biasanya bersifat rasionalisasi, maksudnya disini suatu bentuk pemikiran yang menjadikan seseorang yang melakukan fraud merasa bahwa itu tidak terlalu merugikan pihak lain.

PT.Go-Jek memberikan bonus kepada driver yang telah menyelesaikan pekerjaannya dengan memberikan insentif, karena harus mengejar target insentif, maka disini lah rentan terjadinya fraud. Driver melakukan fraud orderan dengan berpura-pura menjadi penumpang dengan handphone yang lain dan sekaligus sebagai driver yang menerima order, setelah mendapatkan order, driver juga bisa memberikan bintang lima kepada dirinya sendiri. Sikap yang tidak bertanggung jawab yang dilakukan oleh salah satu driver memberikan dampak kepada driver lain yang menjalankan pekerjaannya dengan jujur. Driver dituntut untuk menjalankan pekerjaann dengan kejujuran, kebenaran dan tidak merugikan orang lain. Dari kelemahan pada perusahaan Go-Jek tersebut seharusnya pihak perusahaan harus lebih ketat dalam mengurangi tingkat kecurangan dilapangan dengan cara memperbaiki sistem pengendalian internalnya.

Menurut Elder, Randal J. et al. (2012:321) terdapat lima komponen yang membentuk kerangka Pengendalian Internal COSO yaitu lingkungan pengendalian, penilaian risiko, aktivitas pengendalian, informasi dan komunikasi, serta pengawasan. Hal ini menunjukkan bahwa tanpa lingkungan pengendalian yang berjalan dengan efektif maka keempat komponen pengendalian lain tidak akan dapat membentuk hasil Pengendalian Internal yang efektif pula. Berdasarkan hal tersebut, seharusnya manajemen, pemilik dan direksi dalam perusahaan atau suatu entitas tertentu dapat menerapkan aturan, prosedur maupun kebijakan akuntansi yang dapat menjadi pedoman dalam menjalankan sistem pengendalian internalnya. Semua tujuan pengendalian internal harus mempunyai dasar atau patokan untuk dijalankan. Manajemen akan siap menghadapi segala resiko yang mungkin terjadi apabila pengendalian internal berjalan sesuai dengan yang direncanakan.

Moralitas individu merupakan faktor seseorang melakukan kecurangan, kepercayaan yang diberikan oleh perusahaan kepada karyawan di lapangan tanpa moralitas yang baik akan cenderung terjadinya kecurangan. Semakin buruk moralitas dari karyawan maka semakin tinggi tingkat kecurangan yang akan terjadi sehingga perusahaan harus mempunyai suatu strategi untuk mengurangi kecurangan tersebut. Menurut Amrizal (2004), dalam suatu organisasi perbuatan curang dapat terjadi karena kurangnya kepedulian positif karyawan/aparat terhadap perbuatan salah tersebut dan dirasakan hal yang wajar. Keinginan untuk berfikir positif dari lingkungan kerja sangat diharapkan dapat membangun suatu etika perilaku dan dapat membentuk suatu perusahaan yang kuat. Kurangnya moral dari karyawan membawa pada tindakan kecurangan yang akhirnya menjatuhkan perusahaan tersebut. Teori perkembangan moral adalah teori yang berkaitan dengan moralitas sehingga dalam penelitian ini penulis menerapkan teori model Kohlberg.

Liyanarachi (2009) memaparkan hasil dari beberapa penelitian yangmenunjukkan bahwa tingkat penalaran moral individu akan berpengaruhpada perilaku etis mereka. Apabila seseorang dengan level penalaran yang rendah maka orang tersebut cenderung melakukan kecurangan pada pekerjaannya. Moralitas karyawan yang bernilai positif dapat menjadi keunggulan bersaing bagi perusahaan jasa. Oleh karena itu, demi tujuan perusahaan untuk mendapatkan keuntungan dari konsumenya terlebih dahulu perusahan harus melihat apakah pengendalian internal dan moralitas individu sudah efektif sebab kedua faktor tersebut harus dijadikan fokus utama perusahaan 
karena dapat mencegah terjadinya fraud orderan yang dilakukan oleh karyawan dan perusahaan dapat menjadikan jasanya yang layak digunakan oleh masyarakat.

Dari masalah diatas maka penulis tertarik mengangkat judul penelitian "Pengaruh Pengendalian Internal dan Moralitas Individu Terhadap Fraud Orderan pada Jasa Transportasi Berbasis Online PT. Go-Jek Kota Padang”.

\section{RIVIU LITERATUR DAN HIPOTESIS \\ Theory Fraud Pentagon}

Crowe Howarth (2011) mengatakan bahwa ada lima sifat seseorang melakukan kecurangan. Pressure (Tekanan) dapat dikatakan seseorang melakukan kecurangan karena adanya dorongan dari dalam ataupun luar.Opportunity (Peluang)dapat dikatakan dengan seseorang melakukan kecurangan karena melihat adanya peluang untuk melakukan kecurangan. Rationalization (Rasionalisasi) seseorang melakukan kecurangan karena menganggap bahwa kecurangan yang dia lakukan tidak merugikan orang lain. Competence (kompetensi) seseorang melakukan kecurangan karena memiliki pengetahuan tentang lemahnya pengendalian internal pada perusahaan. Arrogance (Sifat Arogan) seseorang melakukan kecurangan karena menganggap bahwa sistem yang ada di perusahaan tidak akan kuat mengalahkan kemampuan kecurangannya. Kelima sifat itulah yang membuat kenapa seseorang melakukan kecurangan, semua kecurangan tersebut tergantung kepada hati nurani yang ada dalam diri seseorang.

\section{Pengendalian Internal}

Pengendalian internal adalah suatu strategi perusahaan untuk menghadapi aktifitas yang ada di perusahaan, tujuannya harus dapat meningkatkan kegiatan pada perusahaan. setiap perusahan harus memahami dan memastikan bahwa pengendalian internalnya berjalan dengan baik (Elder, 2012). Komponen pengendalian internal COSO (1) Lingkungan pengendalian sangat dibutuhkan untuk melihat aktifitas karyawan, manajemen harus mempunyai rencana untuk pengendalian tersebut. (2) Aktivitas pengendalian digunakan untuk melihat apa manajemen bersiap menghadapi masalah-masalah yang terjadi di perusahaan dan mencari jalan keluar. (3) Penilaian risiko merupakan proses analisis dan identifikasi yangdilakukan manajemen terhadap risikorisiko yang relevan dalampenyusunan laporan keuangan agar informasi yang dihasilkan sesuai. (3) Pembentukan sistem informasi dan komunikasi akuntansi oleh suatuentitas bertujuan untuk memulai, mencatat, memproses danmelaporkan transaksi-transaksi. (5) Perusahaan harus mampu megawasai setiap tindakan kegiatan yang dilakukan karyawan apakah sesuai dengan prodesur yang berlaku. Manajemen harus mampu selalu mengawasi apapun operasional yang ada di perusahaan (Elder, 2012:321).

Lemahnya pengendalian internal pada suatu perusahaan Go-Jek memberikan peluang kepada driver untuk melakukan fraud orderan. Berdasarkan data riset dari Institute for Development of Economics and Finance (INDEF) menunjukkan bahwa $42 \%$ mitra pengemudi di PT.Go-Jek terindikasi fraud. Hal ini menunjukkan bahwa sistem pengendalian internal di perusahaan Go-Jek belum berjalan sebagaimana mestinya. Oleh sebab itu, diperlukan sistem pengendalian internal yang baik agar fraud orderan dapat diminimalisir.Berdasarkan penjelasan di atas, maka hipotesis pertama yang akan di uji adalah sebagai berikut:

H1: Pengendalian internal berpengaruh negatif dan signifikan terhadap fraud orderan transportasi online. 


\section{Moralitas Individu}

Secara umum moralitas adalah hal yang paling mendasar yang digunakan untuk menilai setiap tindakan atau perilaku individu yang bersifat rasional dan sesuai dengan hati nurani. (Liyanarachi, 2009), memaparkan hasil dari beberapa penelitian yangmenunjukkan bahwa tingkat penalaran moral individu akan berpengaruhpada perilaku etis mereka. Apabila seseorang dengan level penalaran yang rendah maka orang tersebut cenderung melakukan kecurangan pada pekerjaannya. Kolhberg (1971) melakukan penelitian berdasarkan kasus dilema moral untukmengamati perbedaan perilaku individu dalam menyikapi persoalan moralyang sama. Kemudian ia membuat klasifikasi ada tiga tahapan penalaran seseorang. Pada tahap pertama (pre-conventional) yaitu tahapan yang palingrendah, individu akan cenderung bertindak karena tunduk dan takut padahukum yang adadalamlingkungan sosialnya.

Selanjutnya conventional pertimbangan moral yang berkaitan dengan pemahamanhukum, aturan sosial di masyarakat. Sementara itu pada tahap tertinggi (post-conventional), individu telahmenunjukkan kematangan moral manajemen yang lebih tinggi. Moral yang baik bagi perusahaan dengan tidak adanya pengawasan dan pengendalian internal dari perusahaan maka peluang atau kesempatan bagi karyawan untuk melakukan kecurangan bisa saja terjadi. Perusahaan harus memikirkan bagaimana caranya agar karyawan memahami arti penting sebuah kejujuran dan selalu mengawasi karyawan dalam bekerja sehingga tujuan perusahaan dapat tercapai. Berdasarkan penjelasan di atas, maka hipotesis kedua yang akan di uji adalah sebagai berikut:

H2: Moralitas individu berpengaruh negatif dan signifikan terhadap fraud orderan transportasi online.

\section{METODOLOGI PENELITIAN}

Penelitian ini penulis menggunakan jenis penelitian kuantitatif, dalam penelitian ini menggunakan metode survery ialah sebuah penelitian yang dilaksanakan dengan langsung kelapangan yang menjadi sampel sehingga penulis mendapatkan data secara detailBerdasarkan tipe masalah penelitian maka disimpulkan ke dalam penelitian deskriptif yang merupakan penelitian dari masalah dari suatu populasi. Sumber data dalam penelitian ini adalah driver GoJek (Go-Car) Kota Padang dengan cara menjawab item-item pertanyaan dalamkuesioner yang mewakili variabel-variabel yang akan diukur sehingga bisa digali secara mendalam tentang Fraud orderan pada transportasi online

Penelitian ini merupakan bentuk penelitian korelasional (Correlational Research) yaitu tipe penelitian dengan masalah berupa hubungan korelasional antara variabel. Subyek yang diteliti adalah driver Go-Jek transportasi online di Kota Padang. Teknik sampel yang digunakan dalam penelitian ini adalah purposive sampling. Sampel dalam penelitian ini adalah driver GoJek Go-Car dan Go-Ride transportasi online di Kota Padang. Jumlah sampel dalam penelitian ini ditentukan menggunakan rumus Cochran (1963) yaitu sebanyak 150 responden.

\section{HASIL DAN PEMBAHASAN}

Hasil uji validitas pada penelitian ini menunjukkan bahwa instrumen variabel sebesar 0,1603 kriteria valid denganr hitung $>$ dari pada $r$ tabel sebesar 0,1603 maka item tersebut dinyatakan valid. Uji reliabilitas pada penelitian ini diketahui bahwa variabel Pengendalian Internal sebesar 0,889; Moralitas Individu adalah 0,869,Fraud Orderan sebesar 0,956 sehingga dapat disimpulkan bahwa item tersebut reliabel lebih besar dari 0,6. 
Dari hasil uji normalitas metode Kolomogrov Smirnov hasil signifikansi sebesar 0,620 dimana taraf signifikansi sebesar 0,05 . Sehingga uji normalitas pada variabel terdistribusi normal.Dari hasil uji multikolonieritas bahwa nilai tolerance $0,632>0,1$ dan (VIF) sebesar 1,583 $<10,00$. Jadi nilai tolerance dan nilai VIF menunjukkan bebas atau tidak ada multikolonieritas dan hasil uji glejser variabel X yaitu Pengendalian Internal dan Moralitas Individu sebesar 0,803 dan 0,321 diatas dari standar signifikansi sebesar 0,05 . Sehingga tidak terjadi heterokedastisitas.

Nilai $\mathrm{R}$ adalah 0,498. Menurut interpretasi korelasi kategori berpengaruhsedangkarena berada pada interval 0,40 - 0,599. Hal ini pengendalian internal dan moralitas individu berpengaruh sedang terhadap fraud orderan. Bahwa nilai $\mathrm{R}^{2}$ sebesar 0,238 , hal ini berarti bahwa $23,8 \%$ fraud orderan dipengaruhi oleh variabel pengendalian internal dan moralitas individu. Sisanyasebesar 76,2\% dipengaruhi oleh variabel lain. Hasil F hitung sebesar 24,304tingkat signifikansi 0,000 lebih kecil dari 0,05 , nilai $\mathrm{F}$ hitung sebesar 24,304 lebih besar darinilai $\mathrm{F}$ tabelnya $3,91(\mathrm{df} 1=3-1=2$ dan $\mathrm{df} 2=150-3=147)$, maka variabel pengendalian internal dan moralitas individu secara bersama-samaberpengaruh terhadap fraud orderan.

Hasil uji t pengendalian internal sebesar 0,415 , karena negatif artinyaterjadi kenaikan nilai pengendalian internal sebesar 1 level akan menurunkan fraud orderan sebesar 0,415.Nilai signifikansi $0,000<0,05$. Koefisien bernilai negatif artinya terjadi hubungan negatif antara pengendalian internal dengan fraud orderan, koefisien variabel moralitas individu sebesar 0,702, karena berjumla negatif artinyaapabila terjadi kenaikan nilai moralitas individu sebesar 1 level maka akan menurunkan fraud orderan sebesar 0,702. Nilai signifikansi 0,016 < 0,05. Koefisien bernilai negatif artinya terjadi hubungan negatif antara moralitas individu dengan fraud orderan.

\section{Pembahasan}

\section{Pengaruh Pengendalian Internal terhadap Fraud Orderan transportasi online}

Hasil penelitian mendukung hipotesis yang pertama (H1) bahwa pengendalian internal berpengaruh negatif dan signifikan terhadapfraud orderan jasa transportasi online. Nilai t hitung yang lebih besar dari t tabel $(3,711>1,976)$ pada tingkat signifikansi 5\%. Selain itu,nilai probabilitas signifikansi sebesar $0,000<0,05$ bahwavariabel pengendalian internal berpengaruh signifikan terhadap fraud orderan. Semakin tinggipengendalian internal maka semakin menurun tingkat kecurangan.

Hasil penelitian inimendukung penelitian sebelumnya oleh Puspasari (2012), yaitu pengendalian internal berpengaruh negatif dan signifikan terhadap kecurangan dengan kata lain bahwasemakin efektif Pengendalian Internal yang ada di perusahaan, semakinrendah kecenderungan seseorang untuk melakukan kecurangandalam perusahaan.

\section{Pengaruh Moralitas Individu terhadap Fraud Orderan transportasi online}

Hasil penelitian mendukung hipotesis yang kedua $(\mathrm{H} 2)$ bahwa moralitas individu berpengaruh negatif dan signifikan terhadapfraud orderan jasa transportasi online. Nilai t hitung yanglebih besar dari $\mathrm{t}$ tabel $(2,439>1,976)$ pada tingkat signifikansi 5\%. Selain itu,nilai probabilitas signifikansi sebesar $0,016<0,05$ juga mengindikasikan bahwavariabel moralitas aparat berpengaruh signifikan terhadap fraud orderan. Bahwa moralitas individu driver PT.GoJek mempunyai pengaruh terhadap fraud orderan pada PT.Go-Jek di Kota Padang dan pengaruhnyasignifikan artinya apabila moralitas individu yang ada pada driver semakin meningkat, bisa menurunkan kecenderungan kecurangan pada PT.Go-Jek Kota Padang.

Hasil penelitian ini sejalan dengan penelitian-penelitian yang dilakukanoleh Puspasari (2012) dan Wilopo (2006), yang menyatakan bahwa moralitas aparat berpengaruh negatif dan 
signifikan terhadap kecurangan. Hasil penelitian ini mengindikasikan bahwa semakintinggi moralitas individu driver PT.Go-Jek di Kota Padang maka kecenderungan untuk melakukan fraud orderan akan menurun dan sebaliknya semakin tinggi kecenderungan untuk melakukan fraud orderan maka akan semakin rendah moralitas individu driver tersebut.

\section{SIMPULAN, KETERBATASAN, DAN SARAN \\ Kesimpulan}

Hasil penelitian dan pengujian hipotesis ini telah dilakukan, makahasil penelitian dapat disimpulkan sebagai berikut:

a. Terdapat pengaruh negatif dan signifikan antara pengendalian internal dengan fraud orderan jasa transportasi online pada PT.Go-Jek di Kota Padang. Hal tersebut dibuktikan dengan $t$ hitung yang lebih besar dari pada t tabelyaitu $-3,711>1,976$ yang mempunyai arah negatif. Selain itu nilai probabilitas signifikansi sebesar 0,000 lebih kecil dari nilai signifikansi yang telah ditentukan yaitu 0,05 , berarti bahwa pengendalian internal berpengaruh negatif dan signifikan terhadap fraud orderan.

b. Terdapat pengaruh negatif dan signifikan antara moralitas individudengan fraud orderan jasa transportasi online pada PT.Go-Jek di Kota Padang, hal tersebut dibuktikan dengan t hitungyang lebih besar dari pada $t$ tabelyaitu $-2,439>1,976$ yang mempunyai arah negatif. Selain itu nilai probabilitas signifikansi sebesar 0,016 lebih kecil dari nilai signifikansi yang telah ditentukan yaitu 0,05 , berarti bahwamoralitas individu berpengaruh negatif dan signifikan terhadap fraud orderan.

\section{Keterbatasan dan Saran}

Penelitian ini hanya beberapa faktor yang mempengaruh fraud orderan, yaitu pengendalian internal dan moralitas individu. Sedangkan masih banyak lagi faktor-faktor yang dapat mempengaruhi fraud orderan yangtidak diteliti dalam penelitian ini. Oleh karena itu sebaiknya PT.Go-Jek menurunkan bonus dari target insentif dan meningkatkan harga ongkos orderan, dikarenakan kecurangan yang sering terjadi hanya untuk mendapatkan insentif tersebut. Sehingga apabila insentif kecil maka driver akan lebih terfokus kepada per orderan dari pada harus mengejar target insentif.

PT.Go-Jek seharusnya tidak hanya melakukan training online tetapi memberikan driver yang baru untuk mendapatkan pelatihan secara langsung dan mengadakan pelatihan terhadap fraud orderan. Dimana berfungsi untuk menanamkan sikap profesionalismeseorang driver dan untuk mengatasi akan adanya kasus fraud yang dilakukan olehpara driver PT.Go-Jek maka perlu adanya pengendalian internal yang baik.

\section{DAFTAR PUSTAKA}

Albrecht, W. Steve. (2014). Iconic Fraud Triangle endures. Fraud Magazine. Association of Certified Fraud Examiners, Inc.

Amrizal. (2004). "Pencegahan dan Pendeteksian Kecurangan oleh Internal Auditor". Jakarta: Direktorat Investigasi BUMN dan BUMD Deputi Bidang Investigasi.

Andi Urfia Awaliah. (2017). "Analisis Pengendalian Internal Dalam Mengatasi Fraud Orderan Pada Transportasi Berbasis Online Di Pt. Gojek Makassar". Skripsi: UIN Alauddin Makassar.

Arikunto, Suharsimi. (2006). Prosedur Penelitian. Jakarta: Rineka Cipta. 
Aviana. Putu Mega Selvya. (2012). "Penerapan Pengendalian Internal dalam Sistem Informasi Akuntansi Berbasis Komputer". Jurnal Ilmiah Mahasiswa Akuntansi. 1(4): $65-70$.

Budiningsih, Asri. (2004). Belajar dan Pembelajaran. Yogyakarta: Rineka Cipta.

Elder, Randal J. et al. (2012). Jasa Audit dan Assurance : Pendekatan Terpadu (Adaptasi Indonesia). (Alih bahasa : Desti Fitriani). Jakarta : Salemba Empat.

E. Sumaryono, (1995). Etika Profesi Hukum, Norma Bagi Penegak Hukum. Yogyakarta:Kanisius.

Gamar, Nur dan Ali Djamhuri. (2015). "Auditor Internal sebagai Dokter Fraud di Pemerintah Daerah". Jurnal Akuntansi Multiparadigma. 6(1): 107-123.

Gujarati, Damodar. (2003). Ekonometri Dasar. Terjemahan: Sumarno Zain, Jakarta: Erlangga.

Hernandez, J. R. dan T. Groot. (2007). Corporate Fraud: Preventive Controls Which Lower Corporate Fraud.Amsterdam Research Centre in Accounting.

Kohlberg, Lawrence (1971). Stages of Moral Development. Yogyakarta:Kanisius.

Hernandez, J. R. dan T. Groot. (2007). Corporate Fraud: Preventive Controls Which Lower Corporate Fraud. Amsterdam Research Centre in Accounting.

Liyanarachchi, Gregory dan Chris Newdick. (2009). "The Impact of Moral Reasoning andRetaliation on Whistle-Blowing: New Zealand Evidence". Journal of BusinessEthics, 89.

Mulyadi. (2001). Sistem Akuntansi Edisi Tiga.Jakarta: Salemba Empat.

Pamungkas, Imang Dapit. (2014). "Pengaruh Religiusitas Dan Rasionalisasi Dalam Mencegah Dan Mendeteksi Kecenderungan Kecurangan Akuntansi”. Jurnal Ekonomi dan Bisnis. 15(2): 48-59.

Puspasari. (2012). "Pengaruh Moralitas Individu dan Pengendalian Internal terhadap Kecenderungan Kecurangan Akuntansi (Studi Eksperimen pada Konteks Pemerintahan Daerah)". Tesis: Universitas GajahMada.

Rahmawati. (2012). "Analisis Pengaruh Faktor Internal Dan Moralitas Manajemen Terhadap Kecenderungan Kecurangan Akuntansi : Studi Pada Dinas Pengelola Keuangan dan Aset Daerah Kota Semarang". Skripsi. Jurusan Akuntansi Universitas Diponegoro.

Sekaran, Uma. (2007). Research Methods for Business 4th Edition. Penerjemah: Kwan Men Yon. Jakarta : Salemba Empat.

Suprajadi, Lusy. (2009). "Teori Kecurangan Fraud Awareness dan Metodologi Untuk Mendeteksi Kecurangan Pelaporan Keuangan”. Bina Ekonomi Majalah Ilmiah Fakultas Ekonomi Unpar. 13(2): 52-58.

Wilopo. (2006). "Analisis Faktor-Faktor yang Berpengaruh Terhadap Kecenderungan Kecurangan Akuntansi : Studi pada Perusahaan Publik dan Badan Usaha Milik Negara (BUMN) di Indonesia”. Jurnal Riset Akuntansi Indonesia Vol.9. 


\section{LAMPIRAN}

Tabel 1

Uji Normalitas

One-Sample Kolmogorov-Smirnov Test

\begin{tabular}{|ll|r|}
\hline & & $\begin{array}{c}\text { Unstandardized } \\
\text { Residual }\end{array}$ \\
\hline Normal Parameters & \\
& & 150 \\
Most Extreme Differences & Mean &, 0000000 \\
& Std. Deviation & 5,56244992 \\
& Absolute &, 062 \\
Kolmogorov-Smirnov Z & Positive &, 062 \\
Asymp. Sig. (2-tailed) & Negative &,- 059 \\
\hline
\end{tabular}

a. Test distribution is Normal.

Sumber: data primer diolah, 2019

Tabel 2

Uji Multikoliearitas

Coefficients $^{a}$

\begin{tabular}{|c|c|c|c|c|c|c|c|c|}
\hline \multirow{2}{*}{\multicolumn{2}{|c|}{ Model }} & \multicolumn{2}{|c|}{$\begin{array}{l}\text { Unstandardized } \\
\text { Coefficients }\end{array}$} & $\begin{array}{l}\text { Standardized } \\
\text { Coefficients }\end{array}$ & \multirow[b]{2}{*}{$t$} & \multirow[b]{2}{*}{ Sig. } & \multicolumn{2}{|c|}{ Collinearity Statistics } \\
\hline & & $\mathrm{B}$ & Std. Error & Beta & & & Tolerance & VIF \\
\hline \multirow[t]{3}{*}{1} & (Constant) & 55,622 & 4,599 & & 12,094 & ,000 & & \\
\hline & P.internal &,- 415 & ,112 &,- 334 & $-3,711$ & ,000 & ,632 & 1,583 \\
\hline & M.individu &,- 702 & ,288 &,- 219 & $-2,439$ & ,016 & ,632 & 1,583 \\
\hline
\end{tabular}

a. Dependent Variable: F.orderan

Sumber: data primer diolah, 2019

Tabel 3

Hasil Uji Heterokedastisitas

Coefficients $^{a}$

\begin{tabular}{|c|c|c|c|c|c|c|}
\hline \multirow{2}{*}{\multicolumn{2}{|c|}{ Model }} & \multicolumn{2}{|c|}{ Unstandardized Coefficients } & \multirow{2}{*}{$\begin{array}{c}\begin{array}{c}\text { Standardized } \\
\text { Coefficients }\end{array} \\
\text { Beta } \\
\end{array}$} & \multirow[b]{2}{*}{$\mathrm{t}$} & \multirow[b]{2}{*}{ Sig. } \\
\hline & & $\mathrm{B}$ & Std. Error & & & \\
\hline \multirow[t]{3}{*}{1} & (Constant) & 2,253 & 2,895 & & ,778 & ,438 \\
\hline & P.internal &,- 018 & ,070 &,- 026 &,- 250 & ,803 \\
\hline & M.individu &, 180 &, 181 &, 103 & ,995 & ,321 \\
\hline
\end{tabular}

a. Dependent Variable: RES_2

Sumber: data primer diolah, 2019 


\section{Tabel 4}

\section{Hasil Uji Hipotesis}

Uji R

Model Summary

\begin{tabular}{|l|r|r|r|r|}
\hline Model & $\mathrm{R}$ & R Square & Adjusted R Square & $\begin{array}{c}\text { Std. Error of the } \\
\text { Estimate }\end{array}$ \\
\hline 1 &, $498^{\mathrm{a}}$ &, 248 &, 238 & 5,600 \\
\hline
\end{tabular}

a. Predictors: (Constant), M.individu, P.internal

Sumber: data primer diolah, 2019

\section{Tabel 6}

Uji F

ANOVA $^{b}$

\begin{tabular}{|ll|r|r|r|r|r|}
\hline Model & Sum of Squares & df & Mean Square & \multicolumn{1}{c|}{ F } & Sig. \\
\hline 1 & Regression & 1524,407 & 2 & 762,203 & 24,304 &, $000^{\mathrm{a}}$ \\
& Residual & 4610,187 & 147 & 31,362 & & \\
& Total & 6134,593 & 149 & & & \\
\hline
\end{tabular}

a. Predictors: (Constant), M.individu, P.internal

b. Dependent Variable: F.orderan

Sumber: data primer diolah, 2019

Tabel 6

Uji F

Coefficients $^{\mathrm{a}}$

\begin{tabular}{|c|c|c|c|c|c|c|}
\hline \multirow{2}{*}{\multicolumn{2}{|c|}{ Model }} & \multicolumn{2}{|c|}{ Unstandardized Coefficients } & \multirow{2}{*}{$\begin{array}{c}\begin{array}{c}\text { Standardized } \\
\text { Coefficients }\end{array} \\
\text { Beta }\end{array}$} & \multirow[b]{2}{*}{$\mathrm{t}$} & \multirow[b]{2}{*}{ Sig. } \\
\hline & & $\mathrm{B}$ & Std. Error & & & \\
\hline \multirow[t]{3}{*}{1} & (Constant) & 55,622 & 4,599 & & 12,094 & ,000 \\
\hline & P.internal &,- 415 & ,112 &,- 334 & $-3,711$ & ,000 \\
\hline & M.individu &,- 702 & ,288 &,- 219 & $-2,439$ & ,016 \\
\hline
\end{tabular}

a. Dependent Variable: F.orderan

Sumber: data primer diolah, 2019 